\title{
Stereotactic radiosurgery for pediatric brain arteriovenous malformations: long-term outcomes
}

\author{
Ching-Jen Chen, MD, ${ }^{1}$ Cheng-Chia Lee, MD, PhD, ${ }^{2,3}$ Hideyuki Kano, MD, PhD, ${ }^{4}$ \\ Kathryn N. Kearns, BS, ${ }^{1}$ Dale Ding, MD, ${ }^{5}$ Shih-Wei Tzeng, MD, ${ }^{2}$ Ahmet Atik, MD, ${ }^{6}$ \\ Krishna Joshi, MD, ${ }^{6}$ Gene H. Barnett, MD, ${ }^{6}$ Paul P. Huang, MD, ${ }^{7}$ Douglas Kondziolka, MD, ${ }^{7}$ \\ David Mathieu, MD, ${ }^{8}$ Christian lorio-Morin, MD, PhD, ${ }^{8}$ Inga S. Grills, MD, ${ }^{9}$ Thomas J. Quinn, MD, ${ }^{9}$ \\ Zaid A. Siddiqui, MD, ${ }^{9}$ Kim Marvin, BS, ${ }^{9}$ Caleb Feliciano, MD, ${ }^{10}$ Andrew Faramand, MD, ${ }^{4}$ \\ L. Dade Lunsford, MD, ${ }^{4}$ and Jason P. Sheehan, MD, PhD, ${ }^{1}$ on behalf of the International \\ Radiosurgery Research Foundation
}

${ }^{1}$ Department of Neurological Surgery, University of Virginia Health System, Charlottesville, Virginia; ${ }^{2}$ Department of Neurosurgery, Neurological Institute, Taipei Veterans General Hospital; ${ }^{3}$ School of Medicine, National Yang-Ming University, Taipei, Taiwan; ${ }^{4}$ Department of Neurological Surgery, University of Pittsburgh, Pittsburgh, Pennsylvania; ${ }^{5}$ Department of Neurosurgery, University of Louisville School of Medicine, Louisville, Kentucky; ${ }^{6}$ Department of Neurosurgery, Cleveland Clinic Foundation, Cleveland, Ohio; ${ }^{7}$ Department of Neurosurgery, New York University Langone Medical Center, New York, New York; ${ }^{8}$ Division of Neurosurgery, Centre de recherché du CHUS, University of Sherbrooke, Sherbrooke, Quebec, Canada; 'Department of Radiation Oncology, Beaumont Health System, Royal Oak, Michigan; and ${ }^{10}$ Section of Neurological Surgery, University of Puerto Rico, San Juan, Puerto Rico

OBJECTIVE Contrary to the better described obliteration- and hemorrhage-related data after stereotactic radiosurgery (SRS) of brain arteriovenous malformations (AVMs) in pediatric patients, estimates of the rarer complications, including cyst and tumor formation, are limited in the literature. The aim of the present study was to assess the long-term outcomes and risks of SRS for AVMs in pediatric patients (age < 18 years).

METHODS The authors retrospectively analyzed the International Radiosurgery Research Foundation pediatric AVM database for the years 1987 to 2018. AVM obliteration, post-SRS hemorrhage, cyst formation, and tumor formation were assessed. Cumulative probabilities, adjusted for the competing risk of death, were calculated.

RESULTS The study cohort comprised 539 pediatric AVM patients (mean follow-up 85.8 months). AVM obliteration was observed in $64.3 \%$ of patients, with cumulative probabilities of $63.6 \%(95 \% \mathrm{Cl} 58.8 \%-68.0 \%), 77.1 \%(95 \% \mathrm{Cl} 72.1 \%-$ $81.3 \%$ ), and $88.1 \%$ (95\% Cl 82.5\%-92.0\%) over 5, 10, and 15 years, respectively. Post-SRS hemorrhage was observed in $8.4 \%$ of patients, with cumulative probabilities of $4.9 \%(95 \% \mathrm{Cl} 3.1 \%-7.2 \%), 9.7 \%(95 \% \mathrm{Cl} 6.4 \%-13.7 \%)$, and $14.5 \%$ (95\% Cl 9.5\%-20.5\%) over 5, 10, and 15 years, respectively. Cyst formation was observed in $2.1 \%$ of patients, with cumulative probabilities of 5.5\% (95\% Cl 2.3\%-10.7\%) and 6.9\% (95\% Cl 3.1\%-12.9\%) over 10 and 15 years, respectively. Meningiomas were observed in 2 patients $(0.4 \%)$ at 10 and 12 years after SRS, with a cumulative probability of $3.1 \%$ (95\% Cl 0.6\%-9.7\%) over 15 years.

CONCLUSIONS AVM obliteration can be expected after SRS in the majority of the pediatric population, with a relatively low risk of hemorrhage during the latency period. Cyst and benign tumor formation after SRS can be observed in 7\% and $3 \%$ of patients over 15 years, respectively. Longitudinal surveillance for delayed neoplasia is prudent despite its low incidence.

https://thejns.org/doi/abs/10.3171/2019.12.PEDS19595

KEYWORDS arteriovenous malformation; complication; cyst; neoplasm; pediatric; radiation; radiosurgery; stroke; vascular disorders

ABBREVIATIONS AVM = arteriovenous malformation; EBRT = external-beam radiation therapy; IRRF = International Radiosurgery Research Foundation; RIC = radiationinduced change; SM = Spetzler-Martin; SRS = stereotactic radiosurgery.

SUBMITTED October 7, 2019. ACCEPTED December 12, 2019.

INCLUDE WHEN CITING Published online February 7, 2020; DOI: 10.3171/2019.12.PEDS19595. 
B RAIN arteriovenous malformations (AVMs) are responsible for approximately $50 \%$ of all spontaneous intracranial hemorrhages occurring in the pediatric population (age $<18$ years). ${ }^{19}$ The substantial cumulative risk of AVM hemorrhage over a child's lifetime generally outweighs the risk of intervention, which generally favors an aggressive approach toward AVM management in the pediatric population. ${ }^{1,18}$ Stereotactic radiosurgery (SRS) is an effective intervention, either primarily or as a component of multimodality treatment, for pediatric AVMs, especially those not amenable to surgery or in patients who are unwilling or unable to undergo surgery. ${ }^{21,25}$ The limitations of existing pediatric AVM studies include single-center data, small sample size, heterogeneous patient populations that include adult patients, lack of time-dependent analysis, and failure to account for the competing risk of death. In order to better inform the long-term outcomes and risks of SRS for pediatric AVMs, we performed a multicenter, retrospective cohort analysis of individual patient data pooled from 8 member institutions of the International Radiosurgery Research Foundation (IRRF).

\section{Methods}

\section{Patient Identification, Ethical Approval of Study, and Informed Consent}

This study follows the guidelines set forth by the STROBE checklist. This study was approved by the IRB at each individual institution, and patient consent was waived by each IRB. We retrospectively reviewed a database of pediatric AVM patients (age $<18$ years at the time of initial SRS) who underwent SRS at 8 institutions participating in the IRRF. Data on pediatric AVM patients from the previous comprehensive IRRF database (1987-2014) were updated retrospectively by each respective institution to include additional patients and follow-up data on outcomes and complications occurring up to and including 2018. ${ }^{6,7}$ Any pediatric AVM patients who were excluded in the previous database due to treatment with repeat SRS or inadequate follow-up were included in this updated database. The current database also included pediatric AVM patients who underwent SRS between 2014 and 2018, and data from additional participating institutions were included. Verification and attestation of data accuracy were performed by each respective institution. Individual patient data from each contributing institution were then deidentified and pooled by an independent third party.

\section{Baseline Data and Variables}

Baseline patient data included patient characteristics, AVM features, and SRS treatment parameters. Eloquent locations included the sensorimotor, language, and visual cortex, hypothalamus and thalamus, internal capsule, brainstem, cerebellar peduncles, and deep cerebellar nuclei. ${ }^{24}$ Deep locations included the thalamus, basal ganglia, and brainstem. ${ }^{28}$ The Spetzler-Martin (SM) grade, modified radiosurgery-based AVM score, and Virginia Radiosurgery AVM Scale score were calculated for each AVM. ${ }^{24,27,28}$

SRS was performed using the Gamma Knife, and the specific model used varied by year and availability at each institution. The SRS technique for AVMs has been previously described ${ }^{30}$ In brief, the patient's calvaria was affixed within a Leksell model $\mathrm{G}$ frame (Elekta $\mathrm{AB}$ ) under anesthesia. The nidal angioarchitecture and spatial anatomy of the AVM were delineated on DSA and thin-slice (slice thickness 1-2 mm) contrast-enhanced MRI or on CTA when MRI was contraindicated.

\section{Follow-Up and Outcomes}

Neuroimaging follow-up, comprising MRI or CTA when MRI was contraindicated, was performed at 6-month intervals for the first 2 years after SRS and then annually thereafter. Patients with complete AVM obliteration on follow-up MRI were recommended to undergo confirmatory DSA. AVM obliteration was defined on MRI as a lack of abnormal flow voids or on DSA as an absence of anomalous arteriovenous shunting.

Radiation-induced changes (RICs) were radiologically defined as perinidal hyperintensities on T2-weighted or FLAIR MRI sequences. Symptomatic RICs were defined as RICs associated with any new or worsening neurological deterioration. Permanently symptomatic RICs were defined as symptomatic RICs without neurological recovery. Post-SRS hemorrhage was defined as any AVM-related intracranial hemorrhage during the latency period (time period between initial SRS treatment and AVM obliteration), regardless of associated neurological symptoms or lack thereof. Hemorrhages that occurred after AVM obliteration were also captured. SRS-associated cyst and tumor formation were also recorded. ${ }^{5}$ The composite endpoint of favorable outcome was defined as AVM obliteration without post-SRS hemorrhage or permanently symptomatic RICs. The follow-up period comprised clinical and neuroimaging follow-up, whichever was longer.

\section{Statistical Analysis}

All statistical analyses were performed using Stata (version 14.2; StataCorp). The follow-up duration was defined as the time interval from SRS to death or last follow-up. Rates of defined outcomes and complications, comprising favorable outcome, AVM obliteration, post-SRS hemorrhage, RICs (radiological, symptomatic, and permanent), cyst formation, and tumor formation, were reported as percentages. Incidences of post-SRS hemorrhage, cyst formation, and tumor formation were reported as number of new cases divided by the amount of patient-time at risk with $95 \%$ confidence intervals. To account for the competing risk of death and to avoid biased estimates of incidence, cumulative incidence and associated $95 \%$ CIs of AVM obliteration, post-SRS hemorrhage, cyst formation, and tumor formation were calculated using nonparametric cumulative incidence functions. ${ }^{2,8}$ Subgroup analyses were performed for pediatric AVM patients who underwent single-session SRS (i.e., no repeat SRS) and those who underwent single-session SRS as the only AVM treatment (i.e., no resection, embolization, or repeat SRS). Missing data were not imputed.

\section{Results}

\section{Study Cohort Composition}

The study cohort comprised 539 pediatric patients with 
brain AVMs. The contribution from each participating center included 193 patients from the University of Virginia, 173 patients from Taipei Veterans General Hospital, 135 patients from the University of Pittsburgh, 12 patients from the Cleveland Clinic, 9 patients from the Beaumont Health System, 8 patients from the University of Puerto Rico, 7 patients from New York University, and 2 patients from the University of Sherbrooke.

Table 1 details the patient, AVM, and SRS characteristics of the study cohort. The mean age of patients was 12.8 years, and $47.3 \%$ were female. Prior AVM hemorrhage occurred in $71.6 \%$. Prior AVM interventions included external-beam radiation therapy (EBRT), resection, and embolization in $12.8 \%, 6.1 \%$, and $16.9 \%$, respectively. The mean AVM maximum diameter and nidus volume were $2.6 \mathrm{~cm}$ and $5.9 \mathrm{~cm}^{3}$, respectively. AVMs were localized to eloquent and deep brain areas in $75.9 \%$ and $34 \%$, respectively. AVM-associated arterial aneurysms and deep venous drainage were present in $6.3 \%$ and $64 \%$, respectively. The mean SRS margin dose was $20.2 \mathrm{~Gy}$, and the median number of isocenters was 4. Repeat SRS was performed in $21.4 \%$ of the patients. The repeat SRS were performed for incomplete AVM obliteration after the initial SRS procedure. The number of patients who underwent 2, 3, 4, and 5 SRS procedures was $104,7,1$, and 1 , respectively. The mean follow-up duration after initial SRS was 85.8 months.

\section{Outcomes and Complications of the Overall Cohort}

Table 2 details the outcomes and complications of the study cohort. A favorable outcome was achieved in 57\% of the patients, and AVM obliteration was achieved in $64.3 \%$ of the patients. Of those in whom obliteration was achieved, $12.7 \%$ did not have confirmation by DSA. Of the entire cohort, $3.9 \%$ of the patients had obliteration demonstrated on MRI, but on DSA a residual nidus was present. The cumulative incidence of AVM obliteration after SRS was $63.6 \%$ (95\% CI 58.8\%-68.0\%), $77.1 \%$ (95\% CI $72.1 \%-81.3 \%$ ), and $88.1 \%$ (95\% CI $82.5 \%-92.0 \%$ ) over 5,10 , and 15 years, respectively (Fig. 1A). Of the patients who underwent multiple SRS procedures, obliteration was achieved in $47.8 \%$ at the last follow-up. The incidence of post-SRS hemorrhage was 10.7 (95\% CI 7.8-14.7) per 1000 patient-years. Hemorrhage after AVM obliteration occurred in 6 patients $(1.7 \%$; 5 confirmed by DSA, 1 determined by MRI only) at a median interval of 41.6 months (range 38.1-55.9 months) after obliteration. The cumulative incidence of post-SRS hemorrhage was $4.9 \%$ (95\% CI $3.1 \%-7.2 \%)$, $9.7 \%$ (95\% CI 6.4\%-13.7\%), and $14.5 \%(95 \%$ CI 9.5\%-20.5\%) over 5, 10, and 15 years, respectively (Fig. 1B).

The rates of radiological, symptomatic, and permanently symptomatic RIC were $38.4 \%, 10.3 \%$, and $6.2 \%$, respectively. Delayed cyst formation occurred in $2.1 \%$ at a median interval of 7.6 years after SRS. The incidence of cyst formation was 4.4 (95\% CI 2.5-8.0) per 1000 patientyears. The cumulative incidence of cyst formation was $1.4 \%$ (95\% CI $0.5 \%-3.1 \%$ ), $5.5 \%$ (95\% CI $2.3 \%-10.7 \%$ ), and $6.9 \%$ (95\% CI $3.1 \%-12.9 \%)$ over 5, 10 , and 15 years, respectively (Fig. 1C). Tumor formation was observed in 2 patients $(0.4 \%)$, and both lesions were benign meningiomas detected at 10 and 12 years after SRS. These were managed conservatively. The incidence of tumor formation was 0.8 (95\% CI 0.2-3.2) per 1000 patient-years. The cumulative incidence of tumor formation was $3.1 \%$ (95\% CI $0.6 \%-9.7 \%$ ) over 15 years (Fig. 1D).

\section{Subgroup Analysis of SM Grade I and II AVMs}

Table 3 details the outcomes and complications of SM grade I and II AVMs. A favorable outcome was achieved in 64\%. The cumulative incidence of AVM obliteration after SRS was $75.5 \%$ (95\% CI 67.9\%-81.5\%), $85.3 \%(95 \%$ CI $77.9 \%-90.4 \%$ ), and $95.5 \%$ (95\% CI $80.2 \%-99.0 \%$ ) over 5,10 , and 15 years, respectively. The cumulative incidence of post-SRS hemorrhage was 3.6\% (95\% CI 1.3\%$7.9 \%$ ), $5.5 \%$ (95\% CI $2.0 \%-11.8 \%$ ), and $12.0 \%$ (95\% CI $4.2 \%-24.3 \%$ ) over 5,10 , and 15 years, respectively. The cumulative incidence of cyst formation was $1.5 \%(95 \% \mathrm{CI}$ $0.3 \%-5.0 \%), 5.3 \%$ (95\% CI $0.8 \%-16.4 \%$ ), and $5.3 \%$ (95\% CI $0.8 \%-16.4 \%$ ) over 5,10 , and 15 years, respectively. The cumulative incidence of tumor formation was $4.7 \%$ (95\% CI $0.3 \%-19.6 \%$ ) over 15 years.

\section{Outcomes and Complications of Single-Session SRS}

Single-session SRS was performed to treat 416 pediatric AVMs (Table 1). The mean age of the patients in this subgroup was 12.9 years, and $47.3 \%$ were female. Prior AVM hemorrhage occurred in $71.6 \%$ of the patients. Prior AVM interventions included EBRT, resection, and embolization in $7.5 \%, 5.8 \%$, and $16.6 \%$, respectively. The mean AVM maximum diameter and nidus volume were $2.4 \mathrm{~cm}$ and $5.2 \mathrm{~cm}^{3}$, respectively. AVMs were localized to eloquent and deep brain areas in $74 \%$ and $32 \%$, respectively. AVMassociated arterial aneurysms and deep venous drainage were present in $6.7 \%$ and $61.5 \%$, respectively. The mean SRS margin dose was $20.3 \mathrm{~Gy}$, and the median number of isocenters was 4 . The mean follow-up duration was 76.9 months. A favorable outcome was achieved in $63 \%$ (Table 2). The cumulative incidence of AVM obliteration after SRS was 76.5\% (95\% CI 71.4\%-80.8\%), 83.8\% (95\% CI $78.6 \%-87.8 \%$ ), and $91.7 \%$ (95\% CI $85.9 \%-95.2 \%$ ) over 5,10 , and 15 years, respectively (Fig. 2A). The incidence of post-SRS hemorrhage was 7.2 (95\% CI 4.5-11.4) per 1000 patient-years. The cumulative incidence of post-SRS hemorrhage was $4.2 \%$ (95\% CI 2.3\%-6.8\%), 5.3\% (95\% CI $2.8 \%-8.9 \%$ ), and $7.1 \%$ (95\% CI $3.4 \%-12.7 \%$ ) over 5,10 , and 15 years, respectively (Fig. 2B).

The rates of radiological, symptomatic, and permanently symptomatic RICs were $36.5 \%, 8.5 \%$, and $5.3 \%$, respectively. Delayed cyst formation occurred in $1.2 \%$ at a median interval of 3 years after SRS. The incidence of cyst formation was 3.1 (95\% CI 1.3-7.4) per 1000 patient-years. The cumulative incidence of cyst formation was $1.3 \%$ (95\% CI $0.3 \%-3.7 \%$ ), $2.7 \%$ (95\% CI $0.7 \%-7.2 \%$ ), and $2.7 \%$ (95\% CI $0.7 \%-7.2 \%$ ) over 5, 10, and 15 years, respectively (Fig. 2C). The incidence of tumor formation was 0.6 (95\% CI 0.09-4.4) per 1000 patient-years. The cumulative incidence of tumor formation was $2.3 \%$ (95\% CI $0.2 \%-10.5 \%$ ) over 15 years (Fig. 2D).

\section{Outcomes and Complications of Single-Session SRS as the Only AVM Treatment}

Single-session SRS was performed as the only AVM 
TABLE 1. Patient, AVM, and SRS characteristics of the study cohort

\begin{tabular}{|c|c|c|c|}
\hline Characteristic & Overall Cohort $(n=539)$ & Single-Session SRS $(n=416)$ & $\begin{array}{c}\text { Single-Session SRS as Only } \\
\text { Treatment }(n=305)\end{array}$ \\
\hline Age: mean; median (SD), yrs & $12.8 ; 13.3(3.7)$ & $12.9 ; 13.4(3.6)$ & $13 ; 13.7(3.7)$ \\
\hline Female, no. (\%) & $255 / 539(47.3)$ & 199/416 (47.8) & $142 / 305(46.6)$ \\
\hline Prior AVM hemorrhage, no. (\%) & $386 / 539(71.6)$ & $298 / 416(71.6)$ & $220 / 305(72.1)$ \\
\hline Prior EBRT, no. (\%) & $69 / 539(12.8)$ & $31 / 416(7.5)$ & - \\
\hline Prior resection, no. (\%) & $33 / 59(6.1)$ & $24 / 416(5.8)$ & - \\
\hline Prior embolization, no. (\%) & $91 / 539(16.9)$ & $69 / 416(16.6)$ & - \\
\hline Max diameter: mean; median (SD), cm & $2.6 ; 2.3(1.4)$ & $2.4 ; 2.2(1.2)$ & $2.4 ; 2.2(1.2)$ \\
\hline Volume: mean; median (SD), $\mathrm{cm}^{3}$ & $5.9 ; 3(10.2)$ & $5.2 ; 2.8(9.1)$ & $5.1 ; 2.9(6.9)$ \\
\hline$\geq 2$ SRS treatments, no. (\%) & $113 / 529(21.4)$ & - & - \\
\hline Max dose: mean; median (SD), Gy* & $36.7 ; 36(7.3)$ & $36.8 ; 36(7.1)$ & $36.4 ; 34(7.3)$ \\
\hline Margin dose: mean; median (SD), Gy* & $20.2 ; 20(3.3)$ & $20.3 ; 20(3.1)$ & $20.1 ; 19.5(3.1)$ \\
\hline Isodose, median (IQR), \%* & $50(50-58)$ & $50(50-59)$ & $51.4(50-58)$ \\
\hline Isocenters, median (IQR), \%* & $4(2-9)$ & $4(2-9)$ & $5(2-10)$ \\
\hline Eloquent location, no. (\%)† & $409 / 539(75.9)$ & $308 / 416(74)$ & $230 / 305(75.4)$ \\
\hline Deep location, no. (\%)‡ & $182 / 535(34)$ & $132 / 413(32)$ & $103 / 302(34.1)$ \\
\hline Aneurysm, no. (\%) & $34 / 539(6.3)$ & $28 / 416(6.7)$ & $19 / 305(6.2)$ \\
\hline Deep venous drainage, no. (\%) & $345 / 539(64)$ & $256 / 416(61.5)$ & 192/305 (63) \\
\hline \multicolumn{4}{|l|}{ SM grade, no. (\%) } \\
\hline I & 49/539 (9.1) & $40 / 416(9.6)$ & $30 / 305(9.8)$ \\
\hline II & $164 / 539(30.4)$ & $136 / 416(32.7)$ & $91 / 305(29.8)$ \\
\hline III & $243 / 539(45.1)$ & $190 / 416(45.7)$ & $145 / 305(47.5)$ \\
\hline IV & $72 / 539(13.4)$ & $45 / 416(10.8)$ & $34 / 305$ (11.2) \\
\hline V & $11 / 539(2)$ & $5 / 416(1.2)$ & $5 / 305(1.6)$ \\
\hline \multicolumn{4}{|l|}{ VRAS, no. (\%) } \\
\hline 0 & $10 / 539(1.9)$ & $8 / 416(1.9)$ & $5 / 305(1.6)$ \\
\hline 1 & $75 / 539(13.9)$ & $63 / 416(15.1)$ & $37 / 305(12.1)$ \\
\hline 2 & $183 / 539(34)$ & $145 / 416(34.9)$ & $115 / 305(37.7)$ \\
\hline 3 & $157 / 539(29.1)$ & $115 / 416(27.6)$ & $81 / 305(26.6)$ \\
\hline 4 & $114 / 539(21.2)$ & $85 / 416(20.4)$ & $67 / 305(22)$ \\
\hline RBAS: mean/median (SD) & $1.0 / 0.8(1.0)$ & $0.9 / 0.8(0.9)$ & $0.9 / 0.8(0.7)$ \\
\hline Follow-up: mean/median (SD, IQR), mos & $85.8 / 68.5(66.6,30.3-127.1)$ & $76.9 / 52.2(65.7,26.4-108.8)$ & $75.8 / 51.3(65.2,25.1-110.4)$ \\
\hline
\end{tabular}

RBAS = modified radiosurgery-based AVM score; VRAS = Virginia Radiosurgery AVM Scale; $-=$ not applicable.

* Initial SRS parameters.

† Sensorimotor, language, and visual cortex; hypothalamus and thalamus; internal capsule; brainstem; cerebellar peduncles; and deep cerebellar nuclei.

$\ddagger$ Thalamus, basal ganglia, and brainstem.

treatment modality in 305 patients (Table 1). The mean age of this subgroup was 13 years, and $46.6 \%$ were female. Prior AVM hemorrhage occurred in $72.1 \%$ of the patients. The mean AVM maximum diameter and nidus volume were 2.4 $\mathrm{cm}$ and $5.1 \mathrm{~cm}^{3}$, respectively. AVMs were localized to eloquent and deep brain areas in $75.4 \%$ and $34.1 \%$, respectively. AVM-associated arterial aneurysms and deep venous drainage were present in $6.2 \%$ and $63 \%$, respectively. The mean SRS margin dose was $20.1 \mathrm{~Gy}$, and the median number of isocenters was 5 . The mean follow-up duration was 75.8 months. A favorable outcome was achieved in $66 \%$ (Table 2). The cumulative incidence of AVM obliteration after SRS was $79.1 \%$ (95\% CI 73.3\%-83.7\%), 87.7\% (95\% CI $81.8 \%-91.8 \%)$, and $93.5 \%$ (95\% CI 87.3\%-96.8\%) over 5,10 , and 15 years, respectively (Fig. 3A). The incidence of post-SRS hemorrhage was 7.1 (95\% CI 4.1-12.2) per 1000 patient-years. The cumulative incidence of post-SRS hemorrhage was $4.0 \%$ (95\% CI 2.0\%-7.1\%), $4.0 \%$ (95\% CI $2.0 \%-7.1 \%$ ), and $6.6 \%$ (95\% CI $2.5 \%-13.5 \%$ ) over 5,10 , and 15 years, respectively (Fig. 3B).

The rates of radiological, symptomatic, and permanently symptomatic RICs were observed in $40.4 \%, 7.3 \%$, and $4.6 \%$ of the patients, respectively. Delayed cyst formation occurred in $1.3 \%$ at a median interval of 2.5 years after SRS. The incidence of cyst formation was 3.5 (95\% CI 1.3-9.3) per 1000 patient-years. The cumulative incidence of cyst formation was $1.9 \%$ (95\% CI $0.5 \%-5.1 \%$ ), $4.0 \%$ (95\% CI 1.0\%-10.7\%), and 4.0\% (95\% CI 1.0\%-10.7\%) over 5, 10, and 15 years, respectively (Fig. 3C). No tumor formation was observed in this subgroup. 
TABLE 2. Outcomes and complications

\begin{tabular}{lccc}
\hline \multicolumn{1}{c}{ Outcome } & Overall Cohort $(\mathrm{n}=539)$ & Single-Session SRS $(\mathrm{n}=416)$ & $\begin{array}{c}\text { Single-Session SRS as Only } \\
\text { Treatment }(\mathrm{n}=305)\end{array}$ \\
\hline Favorable outcome & $307 / 539(57)$ & $261 / 416(62.7)$ & $202 / 305(66.2)$ \\
\hline AVM obliteration & $346 / 539(64.3)$ & $285 / 415(68.7)$ & $219 / 305(71.8)$ \\
\hline Post-SRS hemorrhage & $45 / 539(8.4)$ & $21 / 416(5.1)$ & $14 / 305(4.6)$ \\
\hline Radiological RIC & $202 / 526(38.4)$ & $148 / 406(36.5)$ & $22 / 303(7.3)$ \\
\hline Symptomatic RIC & $55 / 536(10.3)$ & $35 / 413(8.5)$ & $14 / 303(4.6)$ \\
\hline Permanently symptomatic RIC & $33 / 536(6.2)$ & $22 / 413(5.3)$ & $4 / 301(1.3)$ \\
\hline Delayed cyst & $11 / 529(2.1)$ & $5 / 408(1.2)$ & $0 / 297(0)$ \\
\hline Symptomatic & $3 / 522(0.6)$ & $0 / 403(0)$ & $0 / 297(0)$ \\
\hline Required intervention & $2 / 522(0.4)$ & $0 / 403(0)$ & $0 / 301(0)$ \\
\hline Tumor & $2 / 529(0.4)$ & $1 / 408(0.3)$ & \\
\hline
\end{tabular}

Values are presented as the number (\%) of patients.

\section{Discussion}

In this multicenter study, we provided estimates of the long-term outcomes and risks of SRS for AVMs in the pediatric population. With a mean follow-up exceed- ing 7 years in a large cohort of pediatric AVM patients, favorable outcome was achieved in $57 \%$ of the overall population, which included those with previously treated AVMs and those who underwent repeat SRS. The higher rate of favorable outcome in the two subgroup analyses
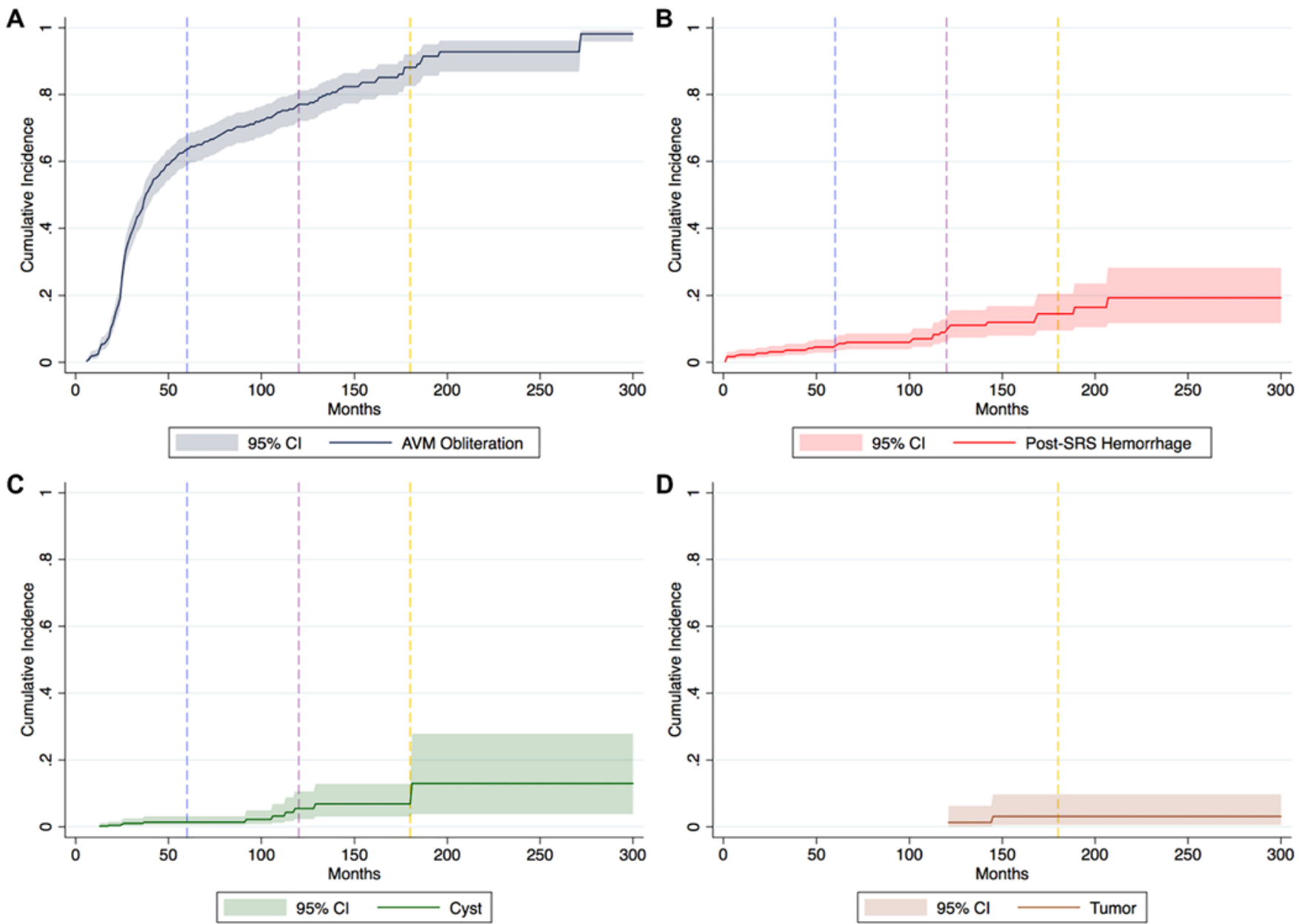

FIG. 1. Cumulative incidence functions and associated $95 \% \mathrm{Cls}$ for AVM obliteration (A), post-SRS hemorrhage (B), cyst formation (C), and tumor formation (D) after SRS for pediatric AVMs in the overall study cohort. Dashed vertical blue, purple, and yellow reference lines denote 5-, 10-, and 15-year time points after SRS, respectively. Figure is available in color online only. 
TABLE 3. Subgroup analysis of SM grade I and II AVMs

\begin{tabular}{lc}
\hline \multicolumn{1}{c}{ Outcome } & SM Grade I \& II AVMs $(n=213)$ \\
\hline Favorable outcome & $136 / 213(63.9)$ \\
\hline AVM obliteration & $148 / 212(69.8)$ \\
\hline Post-SRS hemorrhage & $11 / 213(5.2)$ \\
\hline Radiological RICs & $70 / 209(33.5)$ \\
\hline Symptomatic RICs & $15 / 212(7.1)$ \\
\hline Permanently symptomatic RICs & $10 / 212(4.7)$ \\
\hline Delayed cyst & $3 / 211(1.4)$ \\
\hline Symptomatic & $1 / 210(0.5)$ \\
\hline Required intervention & $1 / 210(0.5)$ \\
\hline Tumor & $1 / 211(0.5)$ \\
\hline
\end{tabular}

Values are presented as the number (\%) of patients.

(63\% for single-session SRS, $66 \%$ for single-session SRS as the only AVM treatment) may reflect selection bias and baseline differences rather than a true treatment effect of single-session, SRS-only therapy. ${ }^{21}$ However, prior nidal embolization has been shown to be a negative prognostic factor for post-SRS AVM obliteration, and repeat SRS may yield worse outcomes than initial SRS..$^{10,21}$

Due to the risk of hemorrhage and its associated morbidity and mortality, complete nidal obliteration remains the primary goal of any AVM treatment. SRS is an effective treatment for pediatric AVMs, especially for those not amenable to surgery, with reported obliteration rates ranging from $60 \%$ to $80 \%$ at $4-5$ years after SRS. ${ }^{9}, 11,13,14,17,23,25,31$ In the current study comprising 539 pediatric AVM patients, obliteration was achieved in $64 \%$ after a mean follow-up of 86 months. To avoid upward bias of incidence estimates, as seen when using the Kaplan-Meier survival function, cumulative incidence functions adjusted for the competing risk of death were used in the estimations of cumulative obliteration, post-SRS hemorrhage, and rates of adverse radiation effects in the current study. ${ }^{2}$ As such, the cumulative obliteration rates of the overall cohort were $64 \%, 77 \%$, and $88 \%$ over 5,10 , and 15 years, respectively.

Despite the long-term efficacy of SRS for AVMs, obliteration occurs in a delayed fashion, and patients remain at risk for AVM hemorrhage during the latency period between SRS and complete nidal occlusion. There-
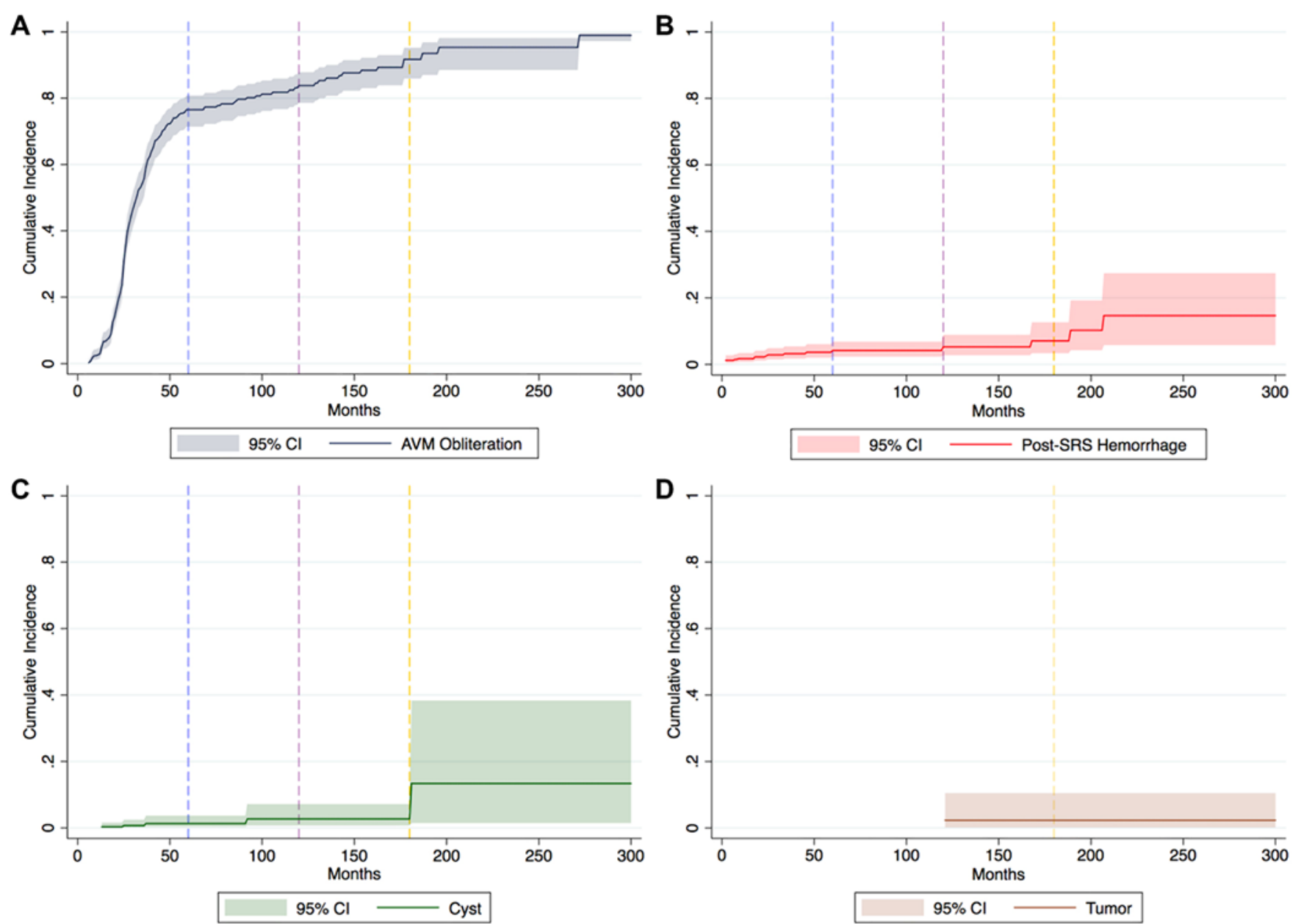

FIG. 2. Cumulative incidence functions and associated $95 \% \mathrm{Cls}$ for $\mathrm{AVM}$ obliteration (A), post-SRS hemorrhage (B), cyst formation (C), and tumor formation (D) after SRS for pediatric AVMs in the single-session SRS subgroup. Dashed vertical blue, purple, and yellow reference lines denote 5-, 10-, and 15-year time points after SRS. Figure is available in color online only. 

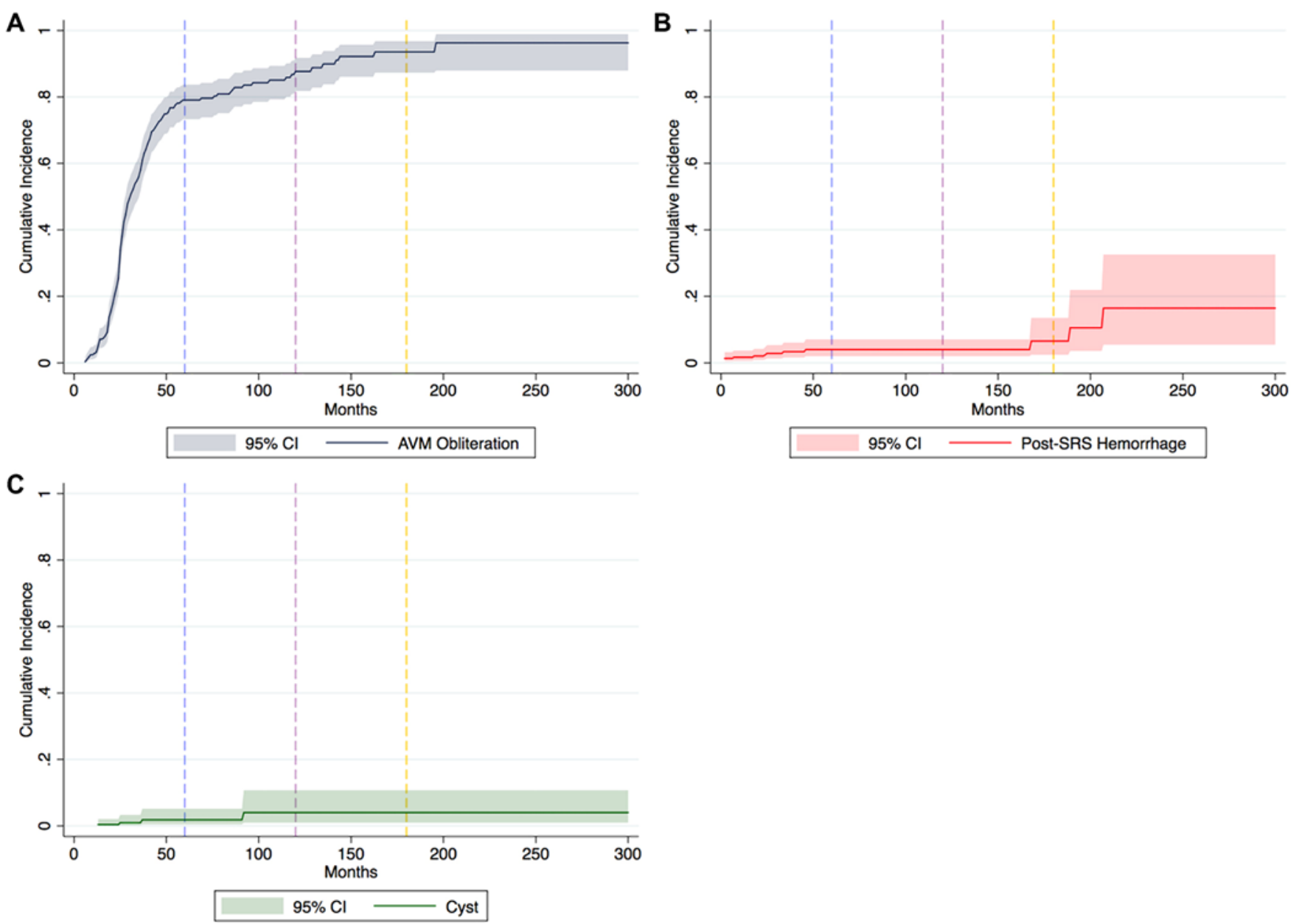

FIG. 3. Cumulative incidence functions and associated $95 \% \mathrm{Cls}$ for AVM obliteration (A), post-SRS hemorrhage (B), and cyst formation (C) after SRS for pediatric AVMs in the single-session SRS as the only AVM treatment modality subgroup. Dashed vertical blue, purple, and yellow reference lines denote 5-, 10-, and 15-year time points after SRS. Figure is available in color online only.

fore, as a safety assessment, post-SRS hemorrhage rates are often compared to the natural history of untreated AVMs. ${ }^{4,9,14,17,18,25}$ Post-SRS hemorrhage occurred in $8.4 \%$ of patients in the current study, resulting in an incidence of 10.7 hemorrhages per 1000 patient-years (annual post-SRS hemorrhage rate of $1.1 \%)$. After adjustment for the competing risk of death, the cumulative incidence of post-SRS hemorrhage was $4.9 \%, 9.7 \%$, and $14.5 \%$ over 5,10 , and 15 years, respectively. Obliteration after SRS is often regarded as a definitive cure. However, AVM recurrence after an apparently curative intervention has been reported, and this phenomenon is more frequently observed in pediatric patients. ${ }^{20} \mathrm{We}$ observed 6 cases of postobliteration hemorrhage (1.7\%) at a median interval of 3.5 years after obliteration. Although these hemorrhages could be attributed to recurrent AVMs or angiographically occult micronidi, they could not be confirmed based on the available data.

RICs are the most frequently observed adverse radiation effect after SRS for AVMs. In a systematic review of 51 studies comprising 6779 AVMs treated with any SRS approach (i.e., single session, staged, or repeat), Ilyas et al. reported radiological, symptomatic, and permanently symptomatic RIC rates of $35.5 \%, 9.2 \%$, and $3.8 \%$, respec- tively. ${ }^{15}$ In the present study, RICs were radiologically evident in $38.4 \%$ of the overall cohort, including symptomatic and permanently symptomatic RICs in $10.3 \%$ and $6.2 \%$, respectively. Although some overlap exists between patients in the systematic review and the current study, pediatric AVM patients appear to be slightly more susceptible to permanent RICs compared to pooled data from the literature..$^{5}$

Due to the relative rarity of post-SRS cysts in AVM patients and the prolonged follow-up necessary for their detection, estimating the incidence of delayed cyst formation has been challenging. The small sample sizes of individual studies and case series dedicated to cyst formation have also hampered an accurate estimation of their cumulative incidence. In a systematic review of 22 studies comprising 2619 patients, Ilyas et al. reported an overall cyst formation rate of $3 \%$, with a mean latency period of 6.5 years after any SRS approach. Among the cysts identified in the review, $32.8 \%$ were symptomatic and $32.8 \%$ required surgical intervention. In the current study, cyst formation was observed in $2.1 \%$ of the cases, and of these post-SRS cysts, $27.3 \%$ were symptomatic and $18.2 \%$ required intervention. The incidence of cyst formation was 4.4 cysts per 
1000 patient-years, with cumulative rates of $1.4 \%, 5.5 \%$, and $6.9 \%$ over 5,10 , and 15 years, respectively. The risk of post-SRS cyst formation in pediatric AVM patients seems to be slightly lower in comparison with pooled data from the literature. ${ }^{16}$

The risk of delayed tumor development after SRS is even more challenging to assess, and the extended interval between SRS and the development of secondary neoplasms may preclude an accurate estimation of risk. However, this risk may be of greater importance in children than in adults, given their relatively greater number of years at risk following SRS. In a previous study from the University of Virginia comprising 1309 AVM patients (pediatric and adult) treated with SRS, Starke et al. reported 3 cases of radiation-related neoplasms, including 2 meningiomas and 1 high-grade glioma, with cumulative incidences of $0 \%, 0.3 \%$, and $2.6 \%$ at 3,10 , and 15 years, respectively. ${ }^{26}$ In a recent multicenter study assessing the risk of SRS-associated intracranial malignancy, the investigators observed no secondary intracranial malignancies among 1089 AVM patients (pediatric and adult) after a median follow-up of 8.1 years. ${ }^{29}$ Although there were no secondary intracranial malignancies in the current study, we found 2 cases $(0.4 \%)$ of SRS-induced meningioma that were previously reported based on neuroimaging characteristics and behavior. ${ }^{22,26}$ Although no secondary intracranial malignancies were detected in the current study, SRSassociated malignant brain tumors have been reported in the literature. ${ }^{3}$ Since this risk appears to be higher than that found in the general population, longitudinal surveillance after SRS remains important. ${ }^{12}$

It is important to note the limitations of this retrospective study. The results are dependent on the accuracy and reliability of data from each participating center and, therefore, may be subject to reporting bias. Due to the nature of each contributing institution as a tertiary referral center for AVM SRS, detailed follow-up data, such as functional, seizure, and educational outcomes, could not be provided for every patient. Our database did not allow differentiation between delayed strokes and RICs. Therefore, we concede that a minority of patients with symptomatic post-SRS complications could have suffered from delayed infarcts rather than RICs. Additionally, the effects of post-SRS hemorrhage on neurological or functional outcomes were not captured. Despite the large sample size and long follow-up duration of the current study, our analyses may still be insufficient for the detection of rare and very delayed SRS-associated complications, such as cyst and tumor formation. Due to the low incidences of cyst and tumor formation, we were unable to identify their respective risk factors. Furthermore, AVM recurrence after angiographically confirmed obliteration, which has been reported predominantly in pediatric patients, was not documented in this study. AVM treatments subsequent to post-SRS hemorrhage were not recorded.

Differences in outcomes and complications between the overall cohort and subgroup analyses may reflect selection biases and differences in baseline characteristics, and therefore, they should not be interpreted as an effect of a particular treatment approach. No direct comparisons against the natural history of pediatric AVMs could be made, as control (untreated) cohort data were not available. Furthermore, it is important to note that SRS is often reserved for AVMs with high surgical risks (i.e., SM grade III-V AVMs) or for patients who refuse craniotomy (i.e., SM grade I and II AVMs). However, this study was also not designed to compare the outcomes of SRS to those of resection for pediatric AVMs. Treatment algorithms for pediatric AVMs are subject to considerable variability, as they are biased by the expertise, experience, and preferences of the participating institutions and responsible physicians. The findings of the current study were limited to the pediatric population, and as such, they should not be generalized to the adult population. Since SM grade II and III AVMs comprised the majority of the study cohort, our results may not be generalizable to pediatric patients with high-grade (i.e., SM grade VI and V) AVMs. The majority of patients were treated at one of the 3 major SRS centers participating in the IRRF, and thus, the reported outcomes may not be generalizable to less experienced centers or to centers employing different techniques.

\section{Conclusions}

Complete obliteration can be expected in $60 \%-80 \%$ of pediatric AVMs treated with SRS over 5 years of followup. The annual post-SRS hemorrhage risk for pediatric AVMs is approximately $1 \%$, which compares favorably with the natural history. Although nearly $40 \%$ of SRStreated pediatric AVM patients will develop neuroimaging evidence of RICs, less than one-third of these cases have neurological manifestations. The cumulative rates of cyst and benign tumor formation were estimated to be $7 \%$ and $3 \%$ over 15 years, respectively. Although SRS-related malignancies were not detected in the pediatric AVM population, longitudinal surveillance in these patients remains prudent.

\section{References}

1. ApSimon HT, Reef H, Phadke RV, Popovic EA: A population-based study of brain arteriovenous malformation: longterm treatment outcomes. Stroke 33:2794-2800, 2002

2. Austin PC, Lee DS, Fine JP: Introduction to the analysis of survival data in the presence of competing risks. Circulation 133:601-609, 2016

3. Berman EL, Eade TN, Brown D, Weaver M, Glass J, Zorman $\mathrm{G}$, et al: Radiation-induced tumor after stereotactic radiosurgery for an arteriovenous malformation: case report. Neurosurgery 61:E1099, 2007

4. Brown RD Jr, Wiebers DO, Forbes G, O'Fallon WM, Piepgras DG, Marsh WR, et al: The natural history of unruptured intracranial arteriovenous malformations. J Neurosurg 68:352-357, 1988

5. Cahan WG, Woodard HQ, Higinbotham NL, Stewart FW, Coley BL: Sarcoma arising in irradiated bone: report of eleven cases. 1948. Cancer 82:8-34, 1998

6. Chen CJ, Ding D, Kano H, Mathieu D, Kondziolka D, Feliciano C, et al: Stereotactic radiosurgery for pediatric versus adult brain arteriovenous malformations. Stroke 49:19391945,2018

7. Chen CJ, Lee CC, Ding D, Tzeng SW, Kearns KN, Kano H, et al: Stereotactic radiosurgery for unruptured versus ruptured pediatric brain arteriovenous malformations. Stroke 50:2745-2751, 2019 
8. Coviello E: STCOMPET: Stata module to generate cumulative incidence in presence of competing events. Statistical Software Components. Boston: Boston College Department of Economics, 2003 (https://ideas.repec.org/c/boc/bocode/ s431301.html) [Accessed January 2, 2020]

9. Dinca EB, de Lacy P, Yianni J, Rowe J, Radatz MW, Preotiuc-Pietro D, et al: Gamma knife surgery for pediatric arteriovenous malformations: a 25 -year retrospective study. J Neurosurg Pediatr 10:445-450, 2012

10. Ding D, Xu Z, Shih HH, Starke RM, Yen CP, Cohen-Inbar O, et al: Worse outcomes after repeat vs initial stereotactic radiosurgery for cerebral arteriovenous malformations: a retrospective matched-cohort study. Neurosurgery 79:690-700, 2016

11. Ding D, Xu Z, Yen CP, Starke RM, Sheehan JP: Radiosurgery for unruptured cerebral arteriovenous malformations in pediatric patients. Acta Neurochir (Wien) 157:281-291, 2015

12. Dolecek TA, Propp JM, Stroup NE, Kruchko C: CBTRUS statistical report: primary brain and central nervous system tumors diagnosed in the United States in 2005-2009. Neuro Oncol 14 (Suppl 5):v1-v49, 2012

13. Galván De la Cruz OO, Ballesteros-Zebadúa P, Moreno-Jiménez S, Celis MA, García-Garduño OA: Stereotactic radiosurgery for pediatric patients with intracranial arteriovenous malformations: variables that may affect obliteration time and probability. Clin Neurol Neurosurg 129:62-66, 2015

14. Hanakita S, Koga T, Shin M, Igaki H, Saito N: The long-term outcomes of radiosurgery for arteriovenous malformations in pediatric and adolescent populations. J Neurosurg Pediatr 16:222-231, 2015

15. Ilyas A, Chen CJ, Ding D, Buell TJ, Raper DMS, Lee CC, et al: Radiation-induced changes after stereotactic radiosurgery for brain arteriovenous malformations: a systematic review and meta-analysis. Neurosurgery 83:365-376, 2018

16. Ilyas A, Chen CJ, Ding D, Mastorakos P, Taylor DG, Pomeraniec IJ, et al: Cyst formation after stereotactic radiosurgery for brain arteriovenous malformations: a systematic review. J Neurosurg 128:1354-1363, 2018

17. Kano H, Kondziolka D, Flickinger JC, Yang HC, Flannery TJ, Awan NR, et al: Stereotactic radiosurgery for arteriovenous malformations, part 2: management of pediatric patients. J Neurosurg Pediatr 9:1-10, 2012

18. Kim H, Al-Shahi Salman R, McCulloch CE, Stapf C, Young WL: Untreated brain arteriovenous malformation: patientlevel meta-analysis of hemorrhage predictors. Neurology 83:590-597, 2014

19. Meyer-Heim AD, Boltshauser E: Spontaneous intracranial haemorrhage in children: aetiology, presentation and outcome. Brain Dev 25:416-421, 2003

20. Morgan MK, Patel NJ, Simons M, Ritson EA, Heller GZ: Influence of the combination of patient age and deep venous drainage on brain arteriovenous malformation recurrence after surgery. J Neurosurg 117:934-941, 2012

21. Russell D, Peck T, Ding D, Chen CJ, Taylor DG, Starke RM, et al: Stereotactic radiosurgery alone or combined with embolization for brain arteriovenous malformations: a systematic review and meta-analysis. J Neurosurg 128:1338-1348, 2018

22. Sheehan J, Yen CP, Steiner L: Gamma knife surgery-induced meningioma. Report of two cases and review of the literature. J Neurosurg 105:325-329, 2006

23. Sheth SA, Potts MB, Sneed PK, Young WL, Cooke DL, Gupta N, et al: Angiographic features help predict outcome after stereotactic radiosurgery for the treatment of pediatric arteriovenous malformations. Childs Nerv Syst 30:241-247, 2014
24. Spetzler RF, Martin NA: A proposed grading system for arteriovenous malformations. J Neurosurg 65:476-483, 1986

25. Starke RM, Ding D, Kano H, Mathieu D, Huang PP, Feliciano $\mathrm{C}$, et al: International multicenter cohort study of pediatric brain arteriovenous malformations. Part 2: Outcomes after stereotactic radiosurgery. J Neurosurg Pediatr 19:136-148, 2017

26. Starke RM, Yen CP, Chen CJ, Ding D, Mohila CA, Jensen ME, et al: An updated assessment of the risk of radiationinduced neoplasia after radiosurgery of arteriovenous malformations. World Neurosurg 82:395-401, 2014

27. Starke RM, Yen CP, Ding D, Sheehan JP: A practical grading scale for predicting outcome after radiosurgery for arteriovenous malformations: analysis of 1012 treated patients. J Neurosurg 119:981-987, 2013

28. Wegner RE, Oysul K, Pollock BE, Sirin S, Kondziolka D, Niranjan A, et al: A modified radiosurgery-based arteriovenous malformation grading scale and its correlation with outcomes. Int J Radiat Oncol Biol Phys 79:1147-1150, 2011

29. Wolf A, Naylor K, Tam M, Habibi A, Novotny J, Liščák R, et al: Risk of radiation-associated intracranial malignancy after stereotactic radiosurgery: a retrospective, multicentre, cohort study. Lancet Oncol 20:159-164, 2019

30. Yamamoto M, Jimbo M, Ide M, Tanaka N, Lindquist C, Steiner L: Long-term follow-up of radiosurgically treated arteriovenous malformations in children: report of nine cases. Surg Neurol 38:95-100, 1992

31. Zeiler FA, Janik MK, McDonald PJ, Kaufmann AM, Fewer D, Butler J, et al: Gamma Knife radiosurgery for pediatric arteriovenous malformations: a Canadian experience. Can J Neurol Sci 43:82-86, 2016

\section{Disclosures}

Dr. Grills reports less than 5\% stock ownership in Greater Michigan Gamma Knife, where she also serves on the executive board of directors. Dr. Lunsford reports stock ownership in Elekta $\mathrm{AB}$; he is a consultant for Insightec and DSMB. Dr. Kondziolka reports funding from Brainlab for research support in brain tumor imaging (not related to this study).

\section{Author Contributions}

Conception and design: Sheehan, Chen. Acquisition of data: Lee, Kano, Kearns, Tzeng, Atik, Joshi, Huang, Mathieu, Iorio-Morin, Quinn, Siddiqui, Marvin, Feliciano, Faramand. Analysis and interpretation of data: Sheehan, Chen, Ding. Drafting the article: Chen, Ding. Critically revising the article: all authors. Reviewed submitted version of manuscript: all authors. Statistical analysis: Chen. Administrative/technical/material support: Sheehan. Study supervision: Sheehan.

\section{Supplemental Information}

\section{Previous Presentations}

The contents of this study were orally presented at the 67th Annual Meeting of the Congress of Neurological Surgeons, October 19-23, 2019, San Francisco, California.

\section{Correspondence}

Jason P. Sheehan: University of Virginia Health System, Charlottesville, VA. jsheehan@virginia.edu. 